\title{
Methylation of Single Sites within the Herpes Simplex Virus $t k$ Coding Region and the Simian Virus 40 T-Antigen Intron Causes Gene Inactivation
}

\author{
A. GRAESSMANN, ${ }^{*}$ G. SANDBERG, E. GUHL, AND M. GRAESSMANN \\ Institut für Molekularbiologie und Biochemie der Freien Universität, 14195 Berlin, Germany
}

Received 30 August 1993/Returned for modification 21 October 1993/Accepted 15 December 1993

\begin{abstract}
In order to determine whether partial methylation of the herpes simplex virus (HSV) $t k$ gene prevents $t k$ gene expression, the HSV $t k$ gene was cloned as single-stranded DNA. By in vitro second-strand DNA synthesis, specific HSV $t k$ gene segments were methylated, and the hemimethylated DNA molecules were microinjected into thymidine kinase-negative rat 2 cells. Conversion of the hemimethylated DNA into symmetrical methylated DNA and integration into the host genome occurred early after gene transfer, before the cells entered into the $S$ phase. HSV $t k$ gene expression was inhibited either by promoter methylation or by methylation of the coding region. Using the HindIII-SphI HSV $t k$ DNA fragment as a primer for in vitro DNA synthesis, all cytosine residues within the coding region, from +499 to +1309 , were selectively methylated. This specific methylation pattern caused inactivation of the HSV $t k$ gene, while methylation of the cytosine residues within the nucleotide sequence from +811 to +1309 had no effect on HSV $t k$ gene activity. We also methylated single HpaII sites within the HSV $t k$ gene using a specific methylated primer for in vitro DNA synthesis. We found that of the 16 HSV $t k$ HpaII sites, methylation of 6 single sites caused HSV $t k$ inactivation. All six of these "methylationsensitive" sites are within the coding region, including the HpaII-6 site, which is 571 bp downstream from the transcription start site. The sites $\mathrm{HpaII-7} \mathrm{to} \mathrm{HpaII-16}$ were all methylation insensitive. We further inserted separately the methylation-sensitive HSV $t k$ HpaII-6 site and the methylation-insensitive HpaII-13 site as DNA segments (32-mer) into the intron region of the simian virus $40 \mathrm{~T}$ antigen (TaqI site). Methylation of these HpaII sites caused inhibition of simian virus $40 \mathrm{~T}$-antigen synthesis.
\end{abstract}

It is still not clear how eukaryotic cells regulate gene expression during differentiation and in the differentiated state. There is increasing experimental evidence that this requires a wide spectrum of different cis- and trans-acting elements. One of the cis functional elements, crucial for the modulation of gene expression, is the change in the DNA methylation pattern $(3,4,24,25)$. A considerable obstacle is, still, the question of the mechanism by which DNA methylation prevents gene expression. The current model proposes that undermethylation of the DNA within the promoter region is a prerequisite for gene activation (for a review, see reference 11). In vitro experiments have demonstrated that cytosine methylation prevents the binding of certain transcription factors and hence the formation of a functional transcription complex (for a review, see reference 12). DNA hypermethylation can also increase the binding affinity of protein factors, which then may inhibit gene expression $(5,20,21)$. However, in mammalian cells not all genes respond to DNA methylation in a uniform manner. Genes can be classified into at least three different categories. The first category is that of "methylationsensitive" genes, e.g., the herpes simplex virus (HSV) $t k$ gene (35), in which hypermethylation blocks gene expression. However, we have shown that methylation of the sensitive HSV $t k$ DNA per se is not sufficient to inhibit gene expression in vivo. After microinjection into thymidine kinase (TK)-negative rat2 cells, the methylated HSV $t k$ DNA was transcribed with the same efficiency as was the nonmethylated DNA until chromatin formation occurred (7). Furthermore, when methylated chromatin molecules were injected, HSV $t k$ gene expression

\footnotetext{
* Corresponding author. Mailing address: Institut für Molekularbiologie und Biochemie der Freien Universität, Arnimallee 22, 14195 Berlin, Germany.
}

was blocked immediately $(8,10)$. The second category represents genes that are methylation insensitive, e.g., simian virus 40 (SV40). Early SV40 gene expression was not blocked when complete methylated viral DNA was microinjected either into tissue culture cells (e.g., TC7 or rat 2 cells) or into Xenopus oocytes, although the early SV40 promoter region harbors about $70 \%$ of all potential methylation sites of the entire viral genome $(13,15)$. Genes of the third category (e.g., $H-2 K)$ are hypermethylated within the promoter region before gene activation occurs (30).

In this investigation, we asked whether partial methylation of the HSV $t k$ coding region also mediates gene inactivation. By in vitro second-strand DNA synthesis, different HSV $t k$ segments were selectively methylated, and the hemimethylated DNA molecules were microinjected into TK-negative rat2 cells. These experiments have shown that methylation of the cytosine residues within the coding region from +499 to +1309 was sufficient to block HSV $t k$ gene expression. Furthermore, methylation of single $\mathrm{HpaII}$ sites, as far as $571 \mathrm{bp}$ downstream from the transcription start site, blocked expression of the HSV $t k$ chromatin. These results indicate that DNA methylation not only prevents initiation of transcription but may also inhibit transcript elongation.

\section{MATERIALS AND METHODS}

M13 constructs and in vitro DNA synthesis. The $P v u I I$ restriction DNA fragment of the HSV $t k$ gene was inserted into the multiple cloning site of the plasmid pSPT19 (Pharmacia) and propagated in Escherichia coli HB101 as pSPT19-tk. The HSV $t k$ gene was then isolated from pSPT19-tk as the Bam HIHindIII fragment and inserted into the HindIII-BamHI site of the replicative form of the M13mp18 and M13mp19 phage 
DNA, and the single-stranded (ss) DNA was isolated from purified phage particles (M18-tkI; M19-tkI) (10). Secondstrand synthesis was performed in vitro. Twenty-five nanograms of the 17-mer universal M13 primer (BRL) was added per $1 \mu \mathrm{g}$ of M18-tkI or M19-tkI DNA. For annealing of the primer with the ssDNA, the mixture was kept for $5 \mathrm{~min}$ at $95^{\circ} \mathrm{C}, 30 \mathrm{~min}$ at $55^{\circ} \mathrm{C}$, and $30 \mathrm{~min}$ at $37^{\circ} \mathrm{C}$. For DNA synthesis, $6 \mathrm{U}$ of the Klenow fragment of $E$. coli polymerase (BRL) was used for $2 \mu \mathrm{g}$ of DNA. The reaction was carried out overnight at $15^{\circ} \mathrm{C}$ in $70-\mathrm{mM}$ Tris- $\mathrm{HCl}(\mathrm{pH} 7.5)-70 \mathrm{mM} \mathrm{MgCl}_{2}$ with 1.5 $\mathrm{mM}$ each deoxynucleoside triphosphate (dNTP). For synthesis of the hemimethylated DNA (M19-tkII- $\left.\mathrm{CH}_{3} ; \mathrm{M} 18-\mathrm{tkII}-\mathrm{CH}_{3}\right)$, $1.5 \mathrm{mM} 2$ '-deoxy-5-methylcytosine 5 '-triphosphate (5m-dCTP) was used instead of dCTP (10). Preparation of histone octamers and reconstitution of chromatin were done as described elsewhere (8).

Cell culture and microinjection and DNA analysis. TKnegative rat 2 cells grown on glass slides in Dulbecco's modified Eagle medium (DMEM) supplemented with 5\% fetal calf serum were used for all microinjection experiments (32). Details of the microinjection technique are described elsewhere (14). Unless otherwise indicated, 100 cells were injected for each experiment. The HAT medium contains hypoxanthine, aminopterin, and thymidine (BRL).

Restriction enzyme treatment of the cellular DNA was carried out in the appropriate digestion buffer (BRL), and the DNA was further subjected to Southern blot analysis (28). For reactivation of the methylated trans genes in the corresponding cell lines, 5-azacytidine (5-azaC; Sigma) was added to the culture medium for two 48-h periods (final concentration, 1 to $2 \mu \mathrm{g} / \mathrm{ml}$ ), and the same treatment was repeated 1 week later (7).

\section{RESULTS}

Partial methylation of the coding region blocks HSV $t \boldsymbol{k}$ gene expression. Since the current hypothesis proposes that hypermethylation of the promoter region is essential for inhibition of gene expression, we asked whether partial methylation of the coding region may also cause inactivation of the HSV $t k$ gene. Second-strand DNA synthesis offers the unique opportunity to methylate specific DNA segments in vitro. To obtain ss HSV $t k$ DNA molecules for use as a template for in vitro DNA synthesis, the pSPT19-tk BamHI-HindIII fragment (which contains the entire HSV $t k$ gene) was inserted into the replicative form of the M13mp18 and M13mp19 phage DNA, and the ssDNAs (M18-tkI and M19-tkI) were isolated from the purified phage particles. M18-tkI contains the coding DNA strand, and M19-tkI contains the noncoding DNA strand of the HSV $t k$ gene (10). Microinjection experiments revealed that the ssDNA molecules are almost inactive in the recipient cells, as summarized in Table 1. Using the universal M13 primer for in vitro second-strand synthesis, the ss M18-tkI and M19-tkI DNAs were converted into double-stranded (ds) DNA molecules (M18-tkII and M19-tkII). Under the experimental conditions described in Materials and Methods, dsDNA was synthesized with a very high efficiency (Fig. 1, lane 6), and the full length HSV $t k$ gene was obtained by Bam HI and HindIII endonuclease treatment (Fig. 1, lane 9). After microinjection of either the M18-tkII or the M19-tkII DNA into TK-negative rat 2 cells, thymidine incorporation was demonstrable in all injected cells (Table 1) and about 25 to $30 \%$ of the recipient cells were transformed into permanently HAT-medium-positive cell clones, regardless of whether 2 to 4 or 2,000 to 4,000 DNA molecules were injected per cell (Table 2). This demon-
TABLE 1. TK-positive rat2 cells after microinjection of ssDNA and dsDNA

\begin{tabular}{lcccc}
\hline \multirow{2}{*}{ Material injected } & \multicolumn{4}{c}{ \% TK-positive cells for indicated no. of DNA } \\
& molecules injected/cell ${ }^{a}$ \\
\cline { 2 - 5 } & $2-4$ & $20-40$ & $200-400$ & $2,000-4,000$ \\
\hline M18-tkI & 0 & 0 & 0 & $1-2$ \\
M19-tkI & 0 & 0 & 0 & $1-2$ \\
M18-tkI + M19-tkI ${ }^{b}$ & 0 & 0 & $1-2$ & $5-10$ \\
Annealed and treated & $80-90$ & $90-100$ & $90-100$ & ND $^{d}$ \\
$\quad$ M18-tkI or M19-tkI & & & & \\
M19-tkII & $120-130$ & $120-130$ & $120-130$ & $120-130$ \\
\hline
\end{tabular}

${ }^{a}$ The data shown are mean values for three separate injection experiments each with 100 injected cells. The standard deviation was $\pm 10 \%$. In all experiments, the number of injected cells was regarded as $100 \%$, and values exceeding this number represent cell division. After intranuclear DNA injection, $\left[{ }^{3} \mathrm{H}\right]$ thymidine was added to the culture medium for $24 \mathrm{~h}$; thereafter, cells were fixed and processed for autoradiography.

${ }^{b}$ M18-tkI and M19-tkI DNA were mixed 1:1 before microinjection.

c To obtain linear ssDNA molecules, primers (20-mer) which contained either the Bam HI or the HindIII restriction site with the flanking M13 DNA sequence were synthesized in vitro, annealed with M19-tkI or M19-tkI DNA, and treated with the Bam HI and the HindIII endonuclease. The linear DNA molecules were mixed and annealed after heating at $95^{\circ} \mathrm{C}$ for $10 \mathrm{~min}$.

${ }^{d} \mathrm{ND}$, not done.

strates that after intranuclear injection, the transformation efficiency of the dsDNA is gene dose independent.

By the addition of $5 \mathrm{~m}$-dCTP to the reaction mixture instead of dCTP, all cytosine residues of the newly synthesized DNA strand were replaced by $5 \mathrm{~m}$-cytosine (hemimethylated DNA: M18-tkII- $\mathrm{CH}_{3}$ and M19-tkII-CH ). As summarized in Table 2, HAT-medium-positive cell clones were not obtained when fewer than 2,000 to 4,000 hemimethylated DNA molecules

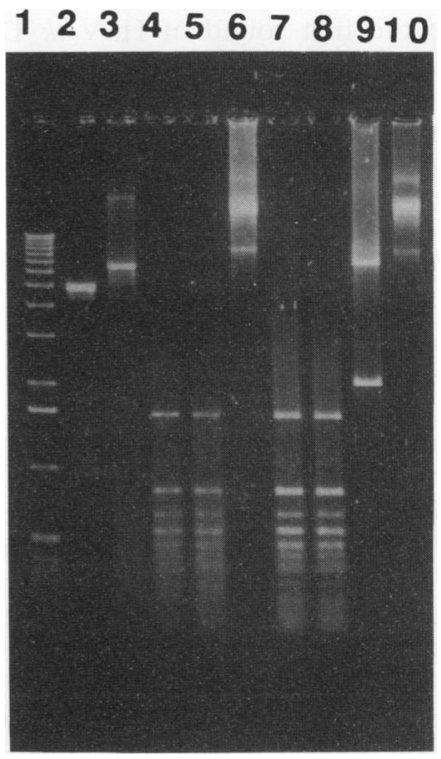

FIG. 1. Gel electrophoresis of in vitro synthesized DNA. Lane 1, size marker (BRL); lane 2, ss M19-tkI DNA; lane 3, replicative-form (RF) M19-tk DNA; lane 4, RF DNA restricted with HpaII endonuclease; lane 5, RF DNA restricted with MspI; lane 6, in vitro synthesized M19-tkII DNA in the nonmethylated form; lane 7, M19tkII DNA restricted with $\mathrm{HpaII}$; lane 8, M19-tkII DNA restricted with MspI; lane 9, M19-tkII DNA restricted with HindIII and Bam HI (the lower band is the HSV $t k$ DNA and the upper band is the M13 DNA); lane 10, M19-tkII- $\mathrm{CH}_{3}$ DNA after $\mathrm{HpaII}$ endonuclease treatment. 
TABLE 2. Transformation efficiency of nonmethylated and methylated HSV $t k$ DNAs after microinjection into rat 2 cells

\begin{tabular}{|c|c|c|c|c|}
\hline \multirow{2}{*}{ Material injected } & \multicolumn{4}{|c|}{$\begin{array}{l}\% \text { HAT-medium-positive cell clones for } \\
\text { indicated no. of DNA molecules injected/cell }\end{array}$} \\
\hline & $2-4$ & $20-40$ & $200-400$ & $2,000-4,000$ \\
\hline M18-tkI & 0 & 0 & 0 & 0.3 \\
\hline M19-tkI & 0 & 0 & 0 & 0.2 \\
\hline M19-tkII & $25-30$ & $25-30$ & $25-30$ & $25-30$ \\
\hline M18-tkII-CH 3 & 0 & 0 & 0 & 0.1 \\
\hline M19-tkII- $\mathrm{CH}_{3}$ & 0 & 0 & 0 & 0.1 \\
\hline M19-tkII-CH +5 -azaC & $20-25$ & $\mathrm{ND}^{b}$ & $20-25$ & $20-25$ \\
\hline
\end{tabular}

${ }^{a}$ Data are means for three separate injection experiments, each with 100 injected cells. After injection, the rat 2 cells were transferred into HAT medium, and the number of colonies was counted 2 weeks later.

${ }^{b} \mathrm{ND}$, not done.

were injected per cell. To exclude the possibility that the hemimethylated DNA was less efficiently integrated into the host genome than was nonmethylated DNA, pM18-tkII- $\mathrm{CH}_{3}$ DNA was coinjected with pSV2neo DNA and G418 resistant cell clones were isolated. Southern blot analysis revealed that the hemimethylated DNA was integrated into the host genome with the same efficiency as was the nonmethylated DNA and that the trans DNA was symmetrically methylated in all analyzed cell lines (data not shown). Furthermore, when the demethylating agent 5-azaC was added to the DMEM directly after injection and left in the medium for $20 \mathrm{~h}$, TK-positive cell clones were obtained with nearly the same efficiency as after injection of the nonmethylated DNA (Table 2). These results demonstrate that the hemimethylated DNA was converted into symmetrical methylated DNA before replication of the M18-tkII- $\mathrm{CH}_{3}$ or M19-tkII- $\mathrm{CH}_{3}$ DNA occurred. Otherwise, the same number of HAT-medium-positive cell clones would have been obtained as after injection of the nonmethylated DNA, because the first round of HSV $t k$ DNA replication would have generated hemimethylated and nonmethylated DNA molecules and hence HAT-medium-resistant cells. As shown elsewhere, methylation of the second DNA strand and integration of the trans DNA into the host genome occurred immediately after intranuclear injection before the cells entered into the $S$ phase (27).

By using different denatured HSV $t k$ DNA fragments as primers, selected HSV $t k$ DNA segments were methylated, and the hemimethylated DNA molecules were microinjected into rat2 cells. As shown in Fig. 2, use of the BglII-Bam HI DNA fragment as a primer allowed the methylation of all cytosine residues of the entire promoter region and of a small 52nucleotide segment of the coding part (Fig. 2, probe 3). The $B g l$ II-HindIII DNA fragment enabled the methylation of all cytosine residues of the coding region minus the 52-nucleotide segment at the $5^{\prime}$ end of the HSV $t k$ coding part (Fig. 2, probe 4). HAT medium selection experiments revealed that methylation of either the promoter or the coding region caused inhibition of HSV $t k$ gene expression (Fig. 2). This observation is in accordance with results reported elsewhere (19). To methylate only the second part of the HSV $t k$ coding region, M19-tkI DNA was hybridized with the HindIII-SphI DNA segment. The HSV tk HindIII-SphI segment corresponds to the entire promoter and to the first 499 nucleotides of the coding region. Used as a primer for in vitro second-strand synthesis, this DNA segment allowed the selective methylation of all cytosine residues within the nucleotide sequence from +499 to +1309 of the HSV $t k$ gene (Fig. 2, strand 5). After microinjection into rat 2 cells, no HAT-medium-positive cell
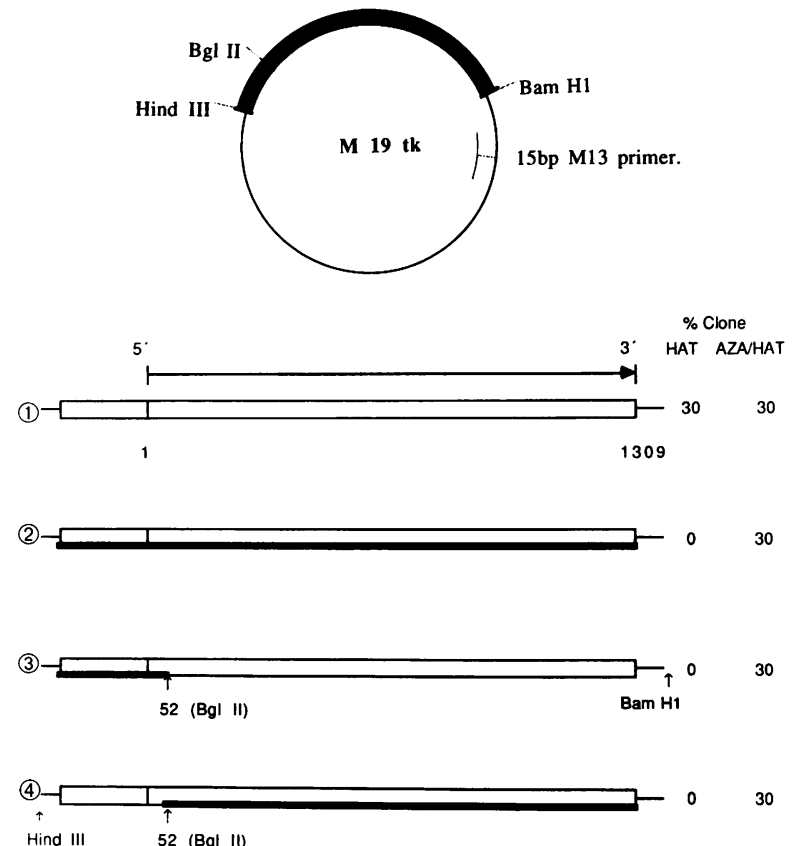

Hind III $52(\mathrm{BgI}$ II)
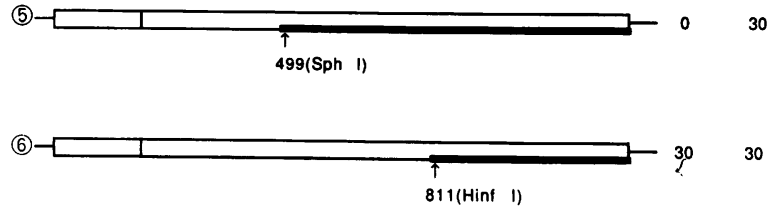

FIG. 2. Partial methylation of the HSV $t k$ gene. The M19-tkI DNA contains the HSV $t k$ gene (dark box) inserted into the HindIII-Bam HI side of the M13mp19 phage DNA. By using the universal M13 primer (BRL), the second DNA strand was synthesized either in the nonmethylated form (probe 1) or in the methylated form (probe 2). By using the HSV $t k$ BglII-BamHI DNA fragment as a primer for second-strand synthesis, the promoter region was methylated (probe 3 ) and the HindIII-BglII DNA fragment allowed methylation of the coding region (probe 4). Partial methylation of the coding region was obtained with the SphI-BamHI (probe 5) or the HindIII-HinfI HSV $t k$ DNA fragment (probe 6) as a primer. The nuclei of rat2 cells were microinjected with 20 to 40 DNA molecules and transferred into HAT medium directly after microinjection. The numbers of HAT-mediumresistant cell clones obtained with (AZA/HAT) or without (HAT) 5 -azaC are listed as percentages of injected cells.

clone was obtained. However, when the culture medium contained 5-azaC for $20 \mathrm{~h}$, TK-positive cell clones were obtained as they were after injection of nonmethylated M19tkII DNA (Fig. 2, strand 5). These results demonstrate that this specific methylation pattern caused inactivation of the HSV $t k$ gene. In contrast, methylation of all cytosine residues within the HSV $t k$ nucleotide sequence from +811 to +1309 had no detectable effect on HSV $t k$ gene activity. This methylation pattern was obtained when the HindIII-HinfI DNA fragment was applied as a primer for in vitro DNA synthesis (Fig. 2, probe 6).

Methylation of single $\mathrm{HpaII}$ sites within the coding region caused HSV $t k$ inactivation. We asked further whether methylation of single cytosine residues within the coding region might also block HSV $t k$ gene expression. As shown in Fig. 3, the HSV $t k$ gene contains 16 HpaII sites; 1 site is within the promoter region and 15 sites are in the coding part. To 


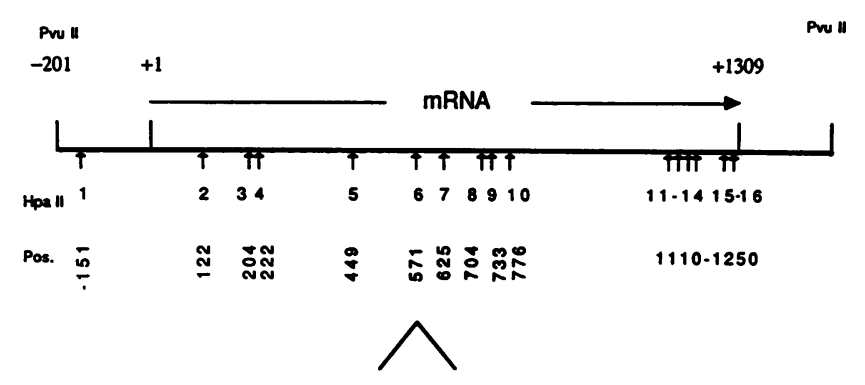

$3-$ TCCCGGĆCCCcG-5

FIG. 3. Schematic representation of the HSV $t k$ gene. The positions of the HpaII sites are indicated. The sequence of the synthetic HpaII-6 primer is shown below. Long arrow, direction of transcription.

obtain DNA molecules with only one HpaII site methylated, 16 oligodeoxynucleotides, corresponding to the $16 \mathrm{HpaII}$ ( $\mathrm{HpaII}-1-\mathrm{CH}_{3}$ to $\left.\mathrm{HpaII}-16-\mathrm{CH}_{3}\right)$ sites, were synthesized in vitro with the internal cytosine of the $\mathrm{CC}^{*} \mathrm{GG}$ tetranucleotide sequence in the methylated form, as shown in Fig. 3 for the oligonucleotide $\mathrm{HpaII}-6-\mathrm{CH}_{3}$. Each of these oligonucleotides was then annealed with M19-tkI DNA and used as primer for in vitro DNA synthesis, with the four standard dNTPs in the reaction mixture. In this way, 16 different preparations were obtained, each with only one cytosine residue methylated (M19-tkII-HpaII-1- $\mathrm{CH}_{3}$ to M19-tkII-HpaII-16- $\mathrm{CH}_{3}$ ). After purification by agarose gel electrophoresis, the DNA was microinjected into rat 2 cells. As summarized in Table 3, selective methylation of the HpaII-2 to HpaII-6 sites caused HSV $t k$ gene inactivation. From about 1,000 cells injected with 2 to 4 DNA molecules, no HAT-medium-positive cell clone was obtained. In contrast, when 5-azaC was added to the cells for $20 \mathrm{~h}$ after injection, HAT-medium-positive cell clones appeared at the same rate as after injection of the nonmethylated DNA (Table 3). Selective methylation of the HpaII-1 site, which is within the promoter region, did not inhibit HSV $t k$ gene expression. This is not surprising, since this site is not within an essential part of the promoter region (data not shown). Furthermore, methylation of the HpaII-7 to HpaII-16 sites, either as single sites or in combination, failed to block HSV $t k$ gene expression.

TABLE 3. Transformation efficiency of nonmethylated and methylated HSV $t k$ DNAs after microinjection into rat 2 cells

\begin{tabular}{|c|c|c|}
\hline \multirow{2}{*}{ Material injected } & \multicolumn{2}{|c|}{$\begin{array}{l}\% \text { HAT-medium-positive cell } \\
\text { clones for indicated medium }\end{array}$} \\
\hline & HAT & $\mathrm{HAT}+5-\mathrm{azaC}^{b}$ \\
\hline M19-tkII- $\mathrm{HpaII-1- \textrm {CH } _ { 3 }}$ & $25-30$ & $25-30$ \\
\hline M19-tkII- $\mathrm{HpaII}-2-\mathrm{CH}_{3}$ & 0 & $25-30$ \\
\hline M19-tkII-HpaII-3- $\mathrm{CH}_{3}$ & 0 & $25-30$ \\
\hline M19-tkII-HpaII-4-CH & $\mathbf{0}$ & $25-30$ \\
\hline M19-tkII-HpaII-5- $\mathrm{CH}_{3}$ & $\mathbf{0}$ & $25-30$ \\
\hline M19-tkII-HpaII-6-CH & 0 & $25-30$ \\
\hline $\begin{array}{l}\text { M19-tkII- } H p a I I-7-\mathrm{CH}_{3} \text { to } \\
\text { M19-tkII-HpaII-16- } \mathrm{CH}_{3}\end{array}$ & $25-30$ & $25-30$ \\
\hline
\end{tabular}

${ }^{a}$ After microinjection, the rat 2 cells were further cultivated in HAT medium Colonies were counted 2 to 3 weeks later. Data are means for three separate injection experiments, each with 100 cells.

b 5 -azaC (final concentration, 1 to $2 \mu \mathrm{g} / \mathrm{ml}$ ) was added for $20 \mathrm{~h}$ to the culture medium.

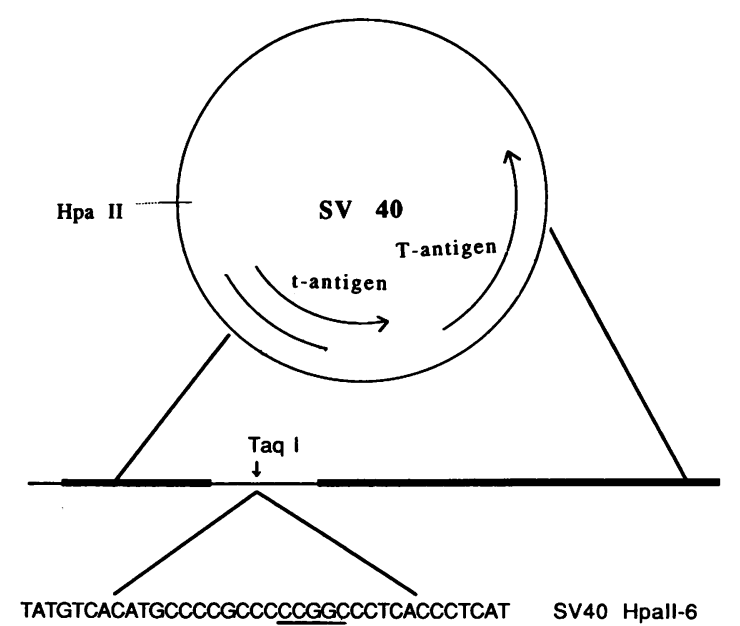

TATGCTGCAACTTACCTCCGGGATGGTCCAGACCCT SV40 Hpall-13

FIG. 4. Schematic representation of the SV40 genome with the HSV tk HpaII-6 and the HSV tk HpaII-13 sites (36-mer) inserted into the TaqI site within the T-antigen intron region. Arrows indicate the locations of the large $\mathrm{T}$ and small $\mathrm{t}$ antigens.

Insertion of the HpaII-6 or the HpaII-13 sequence into the intron region blocks early SV40 gene expression. It is striking that all methylation-sensitive HpaII sites (HpaII-2 to HpaII-6) of the HSV $t k$ gene are in line. This indicates that the relative distance of the methylation sites to the transcription start site may be critical for this inhibitory effect. To obtain further support for this assumption, we synthesized the methylationsensitive HSV $t k$ HpaII-6 and the methylation-insensitive HpaII-13 sites with their flanking sequences as oligomers (32-mer) in vitro, inserted these short DNA segments separately into the TaqI site of the SV40 DNA, and cloned the corresponding constructs (pSV40-HpaII-6 and pSV40-HpaII13). SV40 DNA was chosen for these experiments because the viral genome contains only one HpaII site, which is in the late viral genome part, and the TaqI site is located within the large-T-antigen intron (Fig. 4). Furthermore, the early SV40 promoter is a methylation-insensitive promoter $(13,15)$.

As expected, insertion of the 32-bp HpaII DNA segments into the TaqI site did not affect SV40 T-antigen synthesis after microinjection into either rat2 or TC7 cells. To determine whether methylation of the inserted $\mathrm{HpaII}$ site 512 bp downstream from the transcription start site will block T-antigen synthesis, pSV40-HpaII-6 was methylated with the HpaII methyltransferase (M-HpaII). After methylation, the DNA was further treated with the HpaII endonuclease and purified by agarose gel electrophoresis to exclude contamination with nonmethylated DNA molecules, not detectable by Southern blot analysis. The methylated pSV40- $\mathrm{HpaII}-6-\mathrm{CH}_{3}$ DNA was then microinjected into rat 2 cells, and recipient cells were fixed and stained for $T$ antigen at various intervals after DNA transfer. We found that 24 and $48 \mathrm{~h}$ after injection, the number of T-antigen-positive cells was similar to that after injection of the nonmethylated DNA, but later T-antigen synthesis was inhibited. Since inhibition of HSV $t k$ gene expression by DNA methylation requires chromatin formation, we tested whether methylated pSV40- $\mathrm{HpaII}-6-\mathrm{CH}_{3}$ minichromosomes are immediately inactive after microinjection. To obtain minichromo- 
TABLE 4. SV40 T-antigen synthesis in rat2 cells after intranuclear injection of methylated or nonmethylated SV40 DNA and SV40 chromatin

\begin{tabular}{lcc}
\hline \multirow{2}{*}{ Material injected } & \multicolumn{2}{c}{$\begin{array}{c}\text { \% T-antigen-positive cells with SV40 } \\
\text { component of material injected as }\end{array}$} \\
\cline { 2 - 3 } & DNA & Chromatin \\
\hline SV40 & $100-120$ & $100-120$ \\
SV40-HpaII-6 & $100-120$ & $100-120$ \\
SV40-HpaII-6-CH & $100-120$ & 0 \\
SV40-HpaII-13 & $100-120$ & $100-120$ \\
SV40-HpaII-13-CH & $100-120$ & 0 \\
\hline
\end{tabular}

${ }^{a}$ rat 2 cells were microinjected with 200 to 400 SV40 DNA or SV40 chromatin molecules per cell. Cells were fixed and stained for $\mathrm{T}$ antigen $24 \mathrm{~h}$ after injection. Data are means for three separate injection experiments, each with 100 injected cells. In all experiments, the number of injected cells was regarded as $100 \%$, and values exceeding this number represent cell division.

somes in which the DNA is methylated (methylated chromatin), pSV40-HpaII-6 DNA was methylated with M-HpaII and mixed with purified histone octamers. Minichromosomes were formed during dialysis as described in Materials and Methods. DNA methylation before chromatin reconstitution was essential, because chromatin molecules are very resistant to in vitro methylation. The completeness of chromatin reconstitution was verified for each preparation by electron microscopy (8). $\mathrm{T}$-antigen synthesis was immediately blocked after microinjection of the methylated pSV40 $\mathrm{HpaII}-6-\mathrm{CH}_{3}$ chromatin. In contrast, the nonmethylated chromatin was expressed with the same efficiency as the free DNA, in terms of the onset of $\mathrm{T}$-antigen synthesis and the number of $\mathrm{T}$-antigen-positive cells (Table 4).

To test whether the methylation-insensitive $\mathrm{HpaII}-13$ site can also inhibit early SV40 gene expression, the above experiments were repeated with the pSV40-HpaII-13- $\mathrm{CH}_{3}$ DNA. We found that the methylated HpaII-13 site within the intron region caused inhibition of $\mathrm{T}$-antigen synthesis just as the HpaII-6 site did.

To analyze the effect of methylation weeks after DNA transfer, the methylated pSV40-HpaII-6- $\mathrm{CH}_{3}$ and pSV40-tkHpaII-13- $\mathrm{CH}_{3}$ were coinjected separately with pSPT19-tk DNA, and HAT-positive cell clones were isolated. From each category of injected cells, 10 independent cell clones were isolated and further analyzed. Immunofluorescence staining revealed that $90 \%$ of the clones obtained from cells injected with the nonmethylated DNA were $\mathrm{T}$-antigen positive. In contrast, all clones obtained from the SV40-HpaII-6- $\mathrm{CH}_{3}$ injected cells were $\mathrm{T}$-antigen negative and only one clone of the SV40-HpaII-13- $\mathrm{CH}_{3}$-injected cells expressed the SV40 DNA.

Cellular DNA was extracted from one of the SV40-tk-HpaII6- $\mathrm{CH}_{3}$ and one of the SV40-tk-HpaII-13- $\mathrm{CH}_{3}$ cell clones, and the methylation status of the SV40 DNA was tested by HpaII and MspI endonuclease treatment and by Southern blot analysis. As shown in Fig. 5 for the pSV40-tk-HpaII-13- $\mathrm{CH}_{3}$ line, the cells contain the trans DNA integrated in the their genome with the HpaII sites still methylated. Importantly, Southern blot analysis revealed that the SV40 DNA of the T-antigenpositive pSV40-HpaII-13- $\mathrm{CH}_{3}$ cell line was entirely demethylated (data not shown). To document further that methylation of a single cytosine residue within the intron region of the large $\mathrm{T}$ antigen blocks viral gene expression, 5 -azaC was added to the culture medium (8) of the T-antigen-negative cells. This treatment caused SV40 DNA demethylation (Fig. 5) and induction of SV40 T-antigen synthesis (Fig. 6).

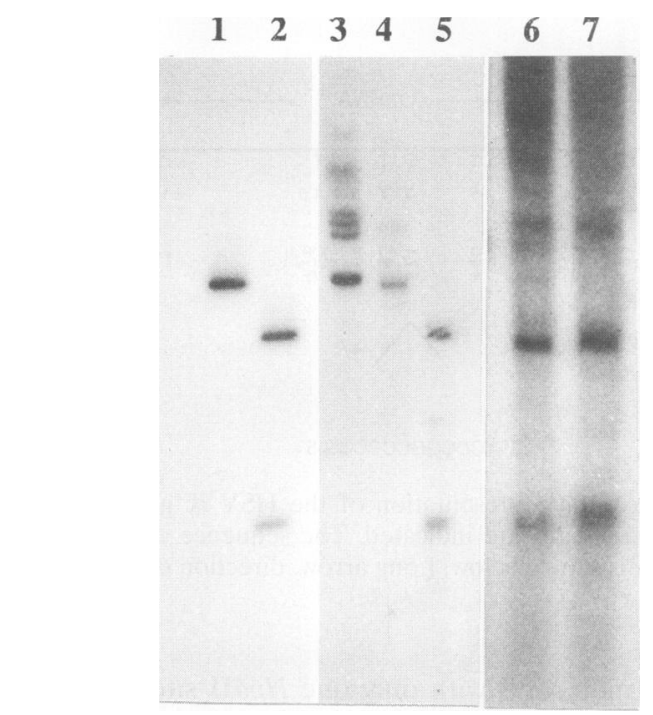

FIG. 5. Southern blot analysis of the pSV40-tk-HpaII-13- $\mathrm{CH}_{3}$ cell line. pSV40-tk-HpaII-13- $\mathrm{CH}_{3}$ DNA was coinjected with pSPT-19 DNA, and HAT-medium-resistant cell clones were isolated. From one T-antigen-negative cell clone, high-molecular-weight DNA was extracted and cleaved with $K p n I$ and Bam HI endonucleases (lane 3). The DNA was then further treated with $H p a I I$ (lane 4) and MspI endonuclease (lane 5). DNA in lane 6 ( $\mathrm{HpaII}$ ) and lane 7 (MspI) was isolated from 5-azaC-treated cells and restricted with the HpaII or MspI enzyme, respectively. Lane 1 contains the SV40 KpnI-BamHI DNA fragment, and lane 2 contains the KpnI-BamHI fragment further cleaved with the $\mathrm{HpaII}$ endonuclease. The blot was hybridized with the ${ }^{32}$ P-labelled SV40 KpnI-BamHI DNA fragment.

\section{DISCUSSION}

The current model proposes that hypermethylation of the promoter region is essential for gene inactivation (for a review, see reference 11). However, our microinjection experiments clearly demonstrated that promoter and coding region methylation causes gene inactivation. HSV $t k$ gene expression was also blocked when the entire promoter and the proximal third of the coding region were not methylated (Fig. 3). Inhibition of gene expression was also obtained when the HSV $t k$ promoter was replaced by the nonmethylated early SV 40 promoter (data not shown). This demonstrates that the inhibitory effect is independent of the promoter strength. This is in contrast to in vitro transcription experiments where the methylation-insensitive SV40 promoter fully overcame the inhibitory effect of DNA methylation (5). Moreover, methylation of single $\mathrm{HpaII}$ sites blocked HSV $t k$ gene expression. All six methylationsensitive sites are within the coding region, including the HpaII-6 site, which is 571 bp downstream from the transcription initiation site. The HpaII-7 to HpaII-16 sites were all methylation insensitive (Fig. 4). Importantly, both the methylation-sensitive HpaII-6 site and the methylation-insensitive HpaII-13 site, when inserted into the SV40 T-antigen intron region (the TaqI site), prevented T-antigen synthesis in the corresponding cell lines, but early SV40 gene expression occurred after 5 -azaC treatment. This indicates that the distance of the methylation site from the promoter region is an important factor for this inhibitory effect.

The observation that gene expression can be inhibited by either promoter methylation or methylation of the coding region suggests that mammalian cells have different options for achieving inhibition at different levels of transcription. How- 

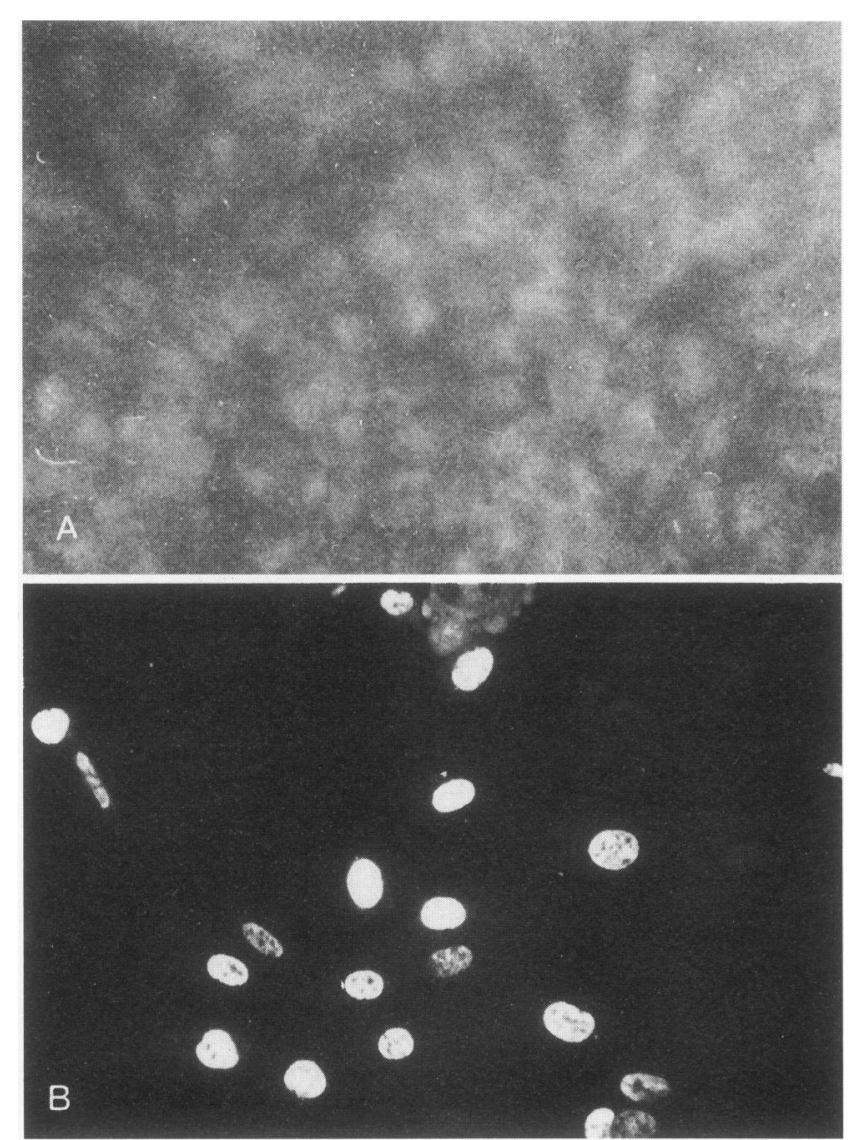

FIG. 6. Induction of SV40 T-antigen synthesis by 5-azaC treat-

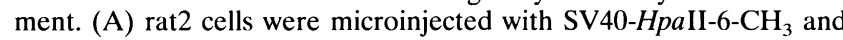
pSPT19-tk DNAs, and HAT-medium-resistant cell clones were selected. All cells are SV40 T-antigen negative. (B) The same cells, $\mathrm{T}$-antigen positive after 5 -azaC treatment.

ever, it is not clear how DNA methylation mediates inhibition of gene expression.

There is experimental evidence that DNA methylation per se does not block the RNA polymerase but that inhibition requires a further interplay of additional cellular proteins $(6,7$, $21,23,24)$. Indeed, it was shown that methylation of cytosine residues can either prevent the binding of certain transcription factors or increase protein binding and eventually block transcription in vitro (for a review, see reference 12). However our microinjection experiments have clearly shown that DNA methylation per se is not sufficient to block HSV $t k$ gene expression in vivo. Inhibition requires that the methylated DNA be converted into chromatin (8).

This observation leads to the general question of the difference between active and inactive chromatin and the role of DNA methylation. One feature frequently associated with active chromatin is the appearance of DNase I-hypersensitive sites within or around the promoter region $(16,31,33,36)$. Although the nature of the DNase hypersensitivity is still not well understood, we analyzed the question of whether methylated chromatin molecules acquire DNase I hypersensitivity. Methylated (pSPT-19-tk, M-HpaII-methylated) and nonmethylated minichromosomes were microinjected into the nuclei of rat 2 cells, and the isolated nuclei were treated with DNase I. We found that the methylated and the nonmethylated chromatin acquired DNase I-hypersensitive sites within the promoter region shortly after microinjection but HSV $t k$ mRNA was not synthesized (13a). Weeks after gene transfer, in the corresponding cell lines, the DNase I hypersensitivity was no longer demonstrable, as already shown elsewhere (18). This observation indicates that generation of DNase I-hypersensitive sites is not sufficient to allow expression of the methylated HSV $t k$ chromatin.

It is assumed not only that the histone octamers are of great importance for DNA packing but that the nucleosomes also play an important role in the regulation of gene expression (17). There is increasing experimental evidence that key nucleosomes can prevent gene expression $(1,22,26)$ and that nucleosome cores are transferred out of the path of the transcribing RNA polymerase (9). Therefore, it is tempting to speculate that under certain conditions DNA methylation interferes with nucleosome mobility and hence prevents transcription.

We may assume that in cases in which sensitive sites are within the coding region, DNA methylation will affect transcript elongation rather than initiation of transcription.

There is increasing evidence that transcript elongation, also, is an important regulatory step in mammalian cells. It has been shown that during transcript elongation, the RNA polymerase can pause or prematurely terminate (for a review, see reference 29). This demonstrates the existence of downstream elements that are used by eukaryotic cells to modulate gene expression. The nature of these pausing (attenuation) sites is not well understood (2). Attenuation sites are mostly within the first several hundred base pairs downstream from the transcription start site and are frequently located within the intron regions (34). It is therefore tempting to speculate that under certain conditions, methylation of specific sites within the coding region eventually creates pausing or termination sites, which then inhibit gene expression of the methylated chromatin at the level of elongation.

\section{ACKNOWLEDGMENTS}

This work was supported by the Deutsche Forschungsgemeinschaft and the Verband der Chemischen Industrie.

\section{REFERENCES}

1. Almer, A., H. Rudolph, A. Hinnen, and W. Hoerz. 1986. Removal of positioned nucleosomes from the yeast $\mathrm{PH} 05$ promoter upon PH05 induction releases additional upstream activating DNA elements. EMBO J. 5:2689-2696.

2. Bengal, E., O. Flores, A. Krauskopf, D. Reinberg, and Y. Aloni. 1991. Role of the mammalian transcription factors IIF, IIS, and IIX during elongation by RNA polymerase II. Mol. Cell Biol. 11:1195-1206.

3. Bestor, T. H. 1993. Methylation patterns in the vertebrate genome. J. NIH Res. 5:57-60.

4. Bird, A. P. 1986. CpG-rich islands and the function of DNA methylation. Nature (London) 351:153-155.

5. Boyes, J., and A. Bird. 1991. DNA methylation inhibits transcription indirectly via a methyl-CpG binding protein. Cell 64:11231134

6. Boyes, J., and A. Bird. 1992. Repression of genes by DNA methylation depends on $\mathrm{CpG}$ density and promoter strength. EMBO J. 11:327-333.

7. Buschhausen, G., M. Graessmann, and A. Graessmann. 1985. Inhibition of herpes simplex thymidine kinase gene expression by DNA methylation is an indirect effect. Nucleic Acids Res. 15: 5503-5513.

8. Buschhausen, G., B. Wittig, M. Graessmann, and A. Graessmann. 1987. Chromatin structure is required to block transcription of the methylated herpes simplex virus thymidine kinase gene. Proc. Natl. Acad. Sci. USA 84:1177-1181.

9. Clark, D. J., and G. Felsenfeld. 1992. A nucleosome core is 
transferred out of the path of a transcribing polymerase. Cell 71:11-22.

10. Deobagkar, D. D., M. Liebler, M. Graessmann, and A. Graessmann. 1990. Hemimethylation of DNA prevents chromatin expression. Proc. Natl. Acad. Sci. USA 87:1691-1695.

11. Doerfler, W. 1993. Pattern of de novo methylation and promoter inhibition: studies on the adenovirus and the human genome, $\mathrm{p}$. 262-300. In J. P. Jost and H. P. Saluz (ed.), DNA methylation: molecular biology and biological significance. EXS 64. Birkhäuser Verlag, Basel.

12. Ehrlich, M., and K. C. Ehrlich. 1993. Effect of DNA methylation on binding of vertebrate and plant proteins to DNA, p. 145-168. In J. P. Jost and H. P. Saluz (ed.), DNA methylation: molecular biology and biological significance. EXS 64. Birkhäuser Verlag, Basel.

13. Goetz, F., K. Schulze-Foster, H. Wagner, H. Kroeger, and D. Simon. 1990. Transcription inhibition by in vitro methylation. Biochim. Biophys. Acta 1087:323-329.

13a.Graessmann, A. Unpublished data.

14. Graessmann, A., and M. Graessmann. 1983. Microinjection of tissue culture cells. Methods Enzymol. 101:482-492.

15. Graessmann, M., A. Graessmann, H. Wagner, E. Werner, and D. Simon. 1983. Complete DNA methylation does not prevent polyoma and simian virus 40 early gene expression. Proc. Natl. Acad. Sci. USA 80:6470-6474.

16. Gross, D. S., and W. T. Garrard. 1988. Nuclease hypersensitive sites in chromatin. Annu. Rev. Biochem. 57:159-197.

17. Grundstein, M. 1990. Nucleosomes: regulators of transcription. Trends Genet. 6:395-400.

18. Keshet, I., J. Lieman-Hurwitz, and H. Cedar. 1986. DNA methylation affects the formation of active chromatin. Cell 44:535-543.

19. Keshet, I., J. Yisraeli, and H. Cedar. 1985. Effect of regional DNA methylation on gene expression. Proc. Natl. Acad. Sci. USA 82:2560-2564.

20. Khan, R., X. Y. Supakar, P. C. Ehrlich, and M. Ehrlich. 1988. Human methylated DNA-binding protein. Determinants of pBR 322 recognition site. J. Biol. Chem. 263:14374-14383.

21. Lewis, J. D., R. R. Meehan, W. J. Henzel, I. Maurer-Fogy, P. Jeppesen, F. Klein, and A. Bird. 1992. Purification, sequence, and cellular localisation of a novel chromosomal protein that binds to methylated DNA. Cell 69:905-914.
22. Lorch, Y., J. W. LaPointe, and R. D. Kornberg. 1987. Nucleosomes inhibit the initiation of transcription but allow chain elongation with the displacement of histones. Cell 49:203-210.

23. Murray, E. J., and F. Grosveld. 1987. Site specific demethylation in the promoter of the human gamma globin does not alleviate methylation mediated suppression. EMBO J. 6:2329-2335.

24. Razin, A., and H. Cedar. 1991. DNA methylation and gene expression. Microbiol. Rev. 55:451-458.

25. Riggs, A., and G. Pfeifer. 1992. X-chromosome inactivation and cell memory. Trends Genet. 8:169-172.

26. Rougvie, A. E., and J. T. Lis. 1988. The RNA polymerase II molecule at the $5^{\prime}$ end of the uninduced hsp 70 gene of $D$. melanogaster is transcriptionally engaged. Cell 54:795-804.

27. Sandberg, G., E. Guhl, M. Graessmann, and A. Graessmann. 1991. After microinjection hemimethylated DNA is converted into symmetrically methylated DNA before DNA replication. FEBS Lett. 283:247-250.

28. Southern, E. M. 1975. Detection of specific sequences among DNA fragments separated by gel electrophoresis. J. Mol. Biol. 98:503-517.

29. Spencer, C. A., and M. Groudine. 1990. Transcription elongation and eukaryotic gene regulation. Oncogene 5:777-785.

30. Tanaka, K., E. Appella, and J. Jay. 1983. Developmental activation of the $\mathrm{H}-2 \mathrm{~K}$ gene is correlated with an increase in DNA methylation. Cell 35:457-465.

31. Thoma, F. 1991. Structural changes in nucleosomes during transcription: strip, split or flip? Trends Genet. 7:175-177.

32. Topp, W. C. 1981. Normal rat cell line deficient in nuclear thymidine kinase. Virology 113:408-411.

33. Weintraub, H., and M. Groudine. 1976. Chromosomal subunits in active genes have an altered conformation. Globin genes are digested by deoxyribonuclease $I$ in red blood cell nuclei but not in fibroblast nuclei. Science 193:848-856.

34. Wiest, D. K., A. Wang, and D. K. Hawley. 1992. Mechanistic studies of transcription arrest at the adenovirus major late attenuation site. J. Biol. Chem. 267:7733-7744.

35. Wigler, M., D. Levy, and M. Perucho. 1981. The somatic replication of DNA methylation. Cell 24:33-40.

36. Wood, W. I., and G. Felsenfeld. 1982. Chromatin structure of the chicken $\beta$-globin region: sensitivity to DNaseI micrococcal nuclease, and DNaseII. J. Biol. Chem. 257:7730-7736. 